\title{
Multifocal high-grade glioma radiotherapy safety and efficacy
}

\author{
Daniel Felix Fleischmann ${ }^{1,2,3 \dagger}{ }^{+}$, Rudolph Schön ${ }^{1 \dagger}$, Stefanie Corradini ${ }^{1}$, Raphael Bodensohn ${ }^{1}$, Indrawati Hadi ${ }^{1}$, \\ Jan Hofmaier ${ }^{1}$, Robert Forbrig ${ }^{4}$, Niklas Thon ${ }^{5}$, Mario Dorostkar ${ }^{6}$, Claus Belka ${ }^{1,2}$ and Maximilian Niyazi ${ }^{1,2^{*}}$
}

\begin{abstract}
Background: Multifocal manifestation of high-grade glioma is a rare disease with very unfavourable prognosis. The pathogenesis of multifocal glioma and pathophysiological differences to unifocal glioma are not fully understood. The optimal treatment of patients suffering from multifocal high-grade glioma is not defined in the current guidelines, therefore individual case series may be helpful as guidance for clinical decision-making.
\end{abstract}

Methods: Patients with multifocal high-grade glioma treated with conventionally fractionated radiation therapy (RT) in our institution with or without concomitant chemotherapy between April 2011 and April 2019 were retrospectively analysed. Multifocality was neuroradiologically assessed and defined as at least two independent contrast-enhancing foci in the MRI T1 contrast-enhanced sequence. IDH mutational status and MGMT methylation status were assessed from histopathology records. GTV, PTV as well as the V30Gy, V45Gy and D2\% volumes of the brain were analysed. Overall and progression-free survival were calculated from the diagnosis until death and from start of radiation therapy until diagnosis of progression of disease in MRI for all patients.

Results: 20 multifocal glioma cases (18 IDH wild-type glioblastoma cases, one diffuse astrocytic glioma, IDH wildtype case with molecular features of glioblastoma and one anaplastic astrocytoma, IDH wild-type case) were included into the analysis. Resection was performed in two cases and stereotactic biopsy only in 18 cases before the start of radiation therapy. At the start of radiation therapy patients were 61 years old in median (range 42-84 years). Histopathological examination showed IDH wild-type in all cases and MGMT promotor methylation in 11 cases (55\%). Prescription schedules were $60 \mathrm{~Gy}(2 \mathrm{~Gy} \times 30)$, $59.4 \mathrm{~Gy}(1.8 \mathrm{~Gy} \times 33), 55 \mathrm{~Gy}(2.2 \mathrm{~Gy} \times 25)$ and $50 \mathrm{~Gy}(2.5 \mathrm{~Gy} \times 20)$ in 15, three, one and one cases, respectively. Concomitant temozolomide chemotherapy was applied in 16 cases, combined temozolomide/lomustine chemotherapy was applied in one case and concomitant bevacizumab therapy in one case. Median number of GTVs was three. Median volume of the sum of the GTVs was $26 \mathrm{~cm}^{3}$. Median volume of the PTV was $425.7 \mathrm{~cm}^{3}$ and median PTV to brain ratio 32.8 percent. Median D2\% of the brain was $61.5 \mathrm{~Gy}$ (range 51.2-62.7) and median V30Gy and V45 of the brain were 59.9 percent (range 33-79.7) and 40.7 percent (range 14.9-64.1), respectively. Median survival was eight months (95\% Kl 3.6-12.4 months) and median progression free survival after initiation of RT five months (95\% Cl 2.8-7.2 months). Grade 2 toxicities were detected in eight cases and grade 3 toxicities in four cases consisting of increasing edema in three cases and one new-onset seizure. One grade 4 toxicity was detected, which was febrile neutropenia related to concomitant chemotherapy.

\footnotetext{
*Correspondence: maximilian.niyazi@med.uni-muenchen.de

${ }^{\dagger}$ Daniel Felix Fleischmann and Rudolph Schön have contributed equally to this work

${ }^{1}$ Department of Radiation Oncology, University Hospital, LMU Munich, Munich, Germany

Full list of author information is available at the end of the article
}

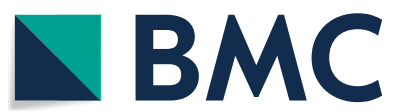

Open Access This article is licensed under a Creative Commons Attribution 4.0 International License, which permits use, sharing, adaptation, distribution and reproduction in any medium or format, as long as you give appropriate credit to the original author(s) and the source, provide a link to the Creative Commons licence, and indicate if changes were made. The images or other third party material in this article are included in the article's Creative Commons licence, unless indicated otherwise in a credit line to the material. If material is not included in the article's Creative Commons licence and your intended use is not permitted by statutory regulation or exceeds the permitted use, you will need to obtain permission directly from the copyright holder. To view a copy of this licence, visit http://creativecommons.org/licenses/by/4.0/. The Creative Commons Public Domain Dedication waiver (http://creativecommons.org/publicdomain/zero/1.0/) applies to the data made available in this article, unless otherwise stated in a credit line to the data. 
Conclusion: Conventionally fractionated RT with concomitant chemotherapy could safely be applied in multifocal high-grade glioma in this case series despite large irradiation treatment fields.

Keywords: Multifocal high-grade glioma, Radiotherapy, Safety, Efficacy

\section{Introduction}

Multifocal high-grade glioma is a primary brain tumour with the most unfavourable prognosis. Median overall survival times are still reported as low as eight months in median, despite aggressive treatment [1]. While the current World Health Organisation (WHO) classification does not refer to multifocal high-grade glioma as a specific subentity [2], multifocal high-grade glioma has been described as being molecular distinct from unifocal highgrade glioma in several histopathological studies [3-6].

Practice changing studies on the treatment of highgrade glioma have included patients with multifocal tumours, but did not analyse the prognosis and therapeutic outcomes of this subset of patients in detail [7-9]. In current guidelines, the therapeutic management of patients with multifocal high-grade glioma is therefore not defined separately from the treatment of unifocal high-grade gliomas [10-12]. Recommendations on the best treatment of multifocal high-grade glioma patients are still limited to institutional case series and database analyses.

Case series and database analyses of the radiation therapy (RT) treatment of multifocal high-grade glioma patients have focused on different fractionation regimes comparing conventionally fractionated with hypofractionated radiotherapy, as well as on the use of concomitant chemotherapy leading to differing recommendations [1, 13-17]. Unfortunately, multifocal high-grade glioma has been defined differently in many retrospective case series and a multitude of different treatment regimens with only limited information about related adverse events have been reported, which limits the comparability of these analyses. In particular, older case series without high-resolution MRI and state-of-the-art RT treatment techniques have limited transferability to the current treatment of patients with multifocal high-grade gliomas.

The aim of the present case series was to evaluate the RT treatment planning parameters, adverse events and the treatment outcome of modern high-precision RT with or without concomitant chemotherapy in order to better understand and improve the treatment of multifocal high-grade glioma patients.

\section{Methods \\ Patients}

Patients with primary diagnosis of a multifocal highgrade glioma, who underwent RT at our department between April 2011 and April 2019 were retrospectively analysed.

\section{Histopathologic examination}

Histopathological confirmation of high-grade glioma in tissue samples obtained by stereotactic biopsy or neurosurgical resection was available for all patients. Mutation of the IDH1 gen and the IDH2 gen and MGMT promotor

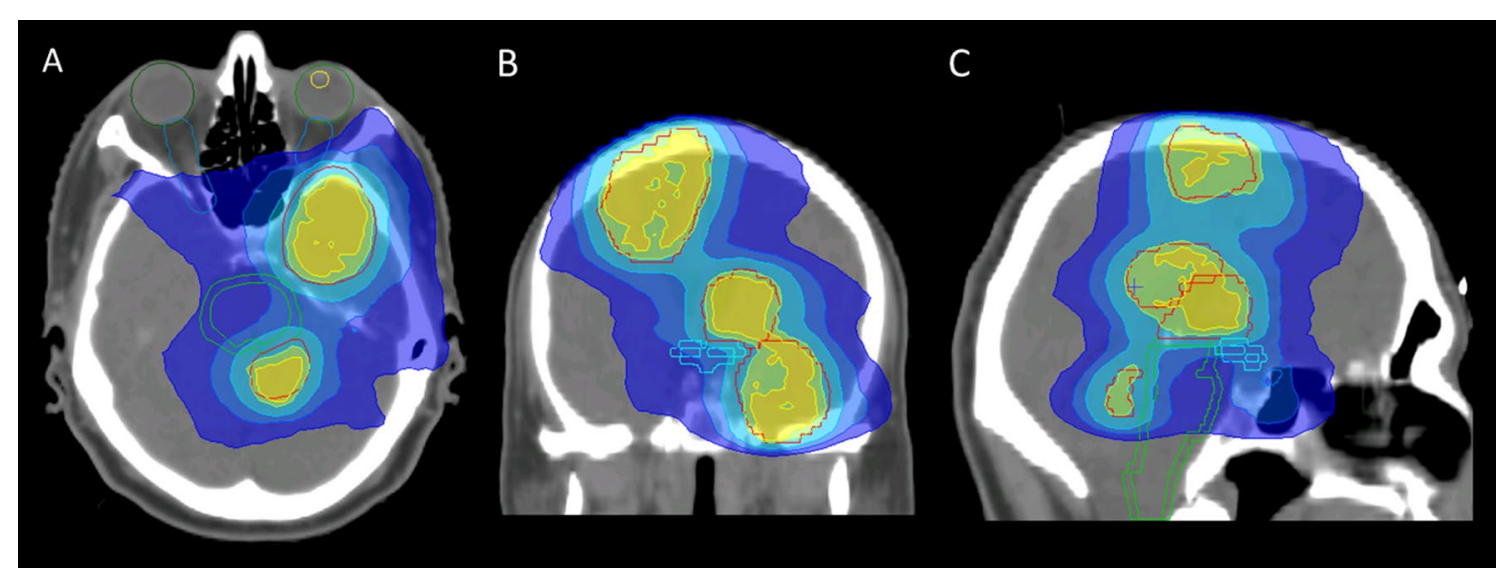

Fig. 1 VMAT plan example. 69 year old male patient with multifocal glioblastoma treated at 5 foci with $60 \mathrm{~Gy}(2 \mathrm{~Gy} \times 30)$ and concomitant temozolomide chemotherapy. Axial (A), coronal (B) and sagittal (C) plane of VMAT plan with PTV (red), 60 Gy isodose line (yellow), 57 Gy isodose line (green), 45 Gy isodose line (light blue), 35 Gy isodose line (blue) and 25 Gy isodose line (dark blue) 

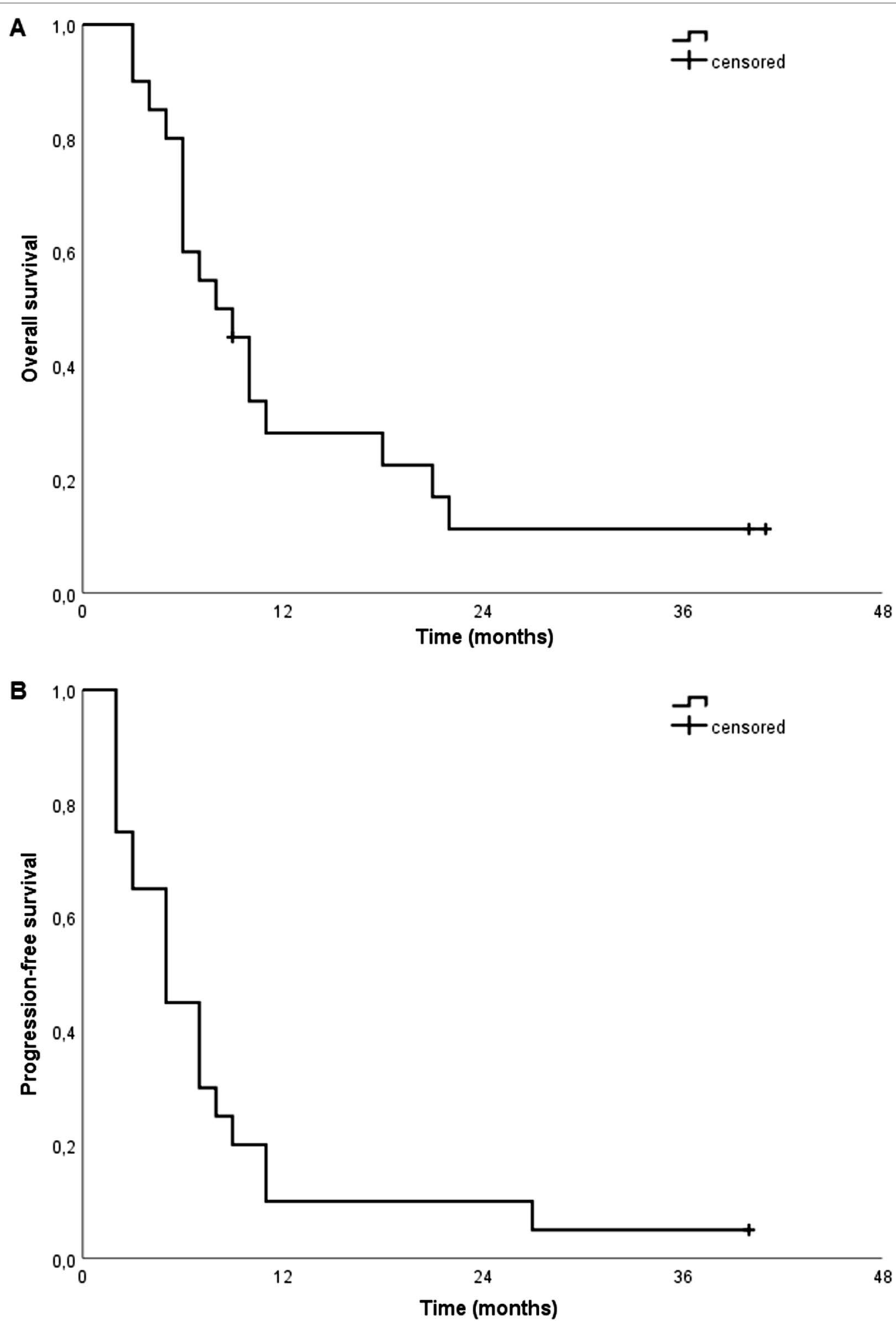

Fig. 2 Overall and progression-free survival. Overall survival after diagnosis of multifocal high-grade glioma and progression-free survival after initiation of radiotherapy 
methylation status at the time of diagnosis were also available for all patients included in this retrospective analysis.

\section{Magnetic resonance imaging and definition of multifocal gliomas}

MRI with contrast-enhanced $\mathrm{T} 1$ and $\mathrm{T} 2$ or FLAIR sequences were conducted prior to RT for all patients. Only patients with multifocal growth pattern at the time of first diagnosis as assessed by an experienced neuroradiologist were included in the study. High-grade gliomas were defined as multifocal, which comprised at least two independent contrast-enhancing foci in the MRI T1 contrast-enhanced sequence.

\section{Radiotherapy protocols}

The indication for RT was based on the consensus recommendation of the interdisciplinary neuro-oncology tumour board in all cases. All patients were treated with limited field irradiation. Prior to radiotherapy, an individual thermoplastic mask was individually made for each patient to ensure reproducibility of patient positioning during planning $\mathrm{CT}$ and the following course of irradiation. The planning CT scan was performed with slice thickness of $3 \mathrm{~mm}$.

Radiation treatment plans included 3D conformal, intensity-modulated radiation therapy (IMRT) and volumetric modulated arc therapy (VMAT) plans (Fig. 1). Four different irradiation regimens were administered: 60 Gy $(2 \mathrm{~Gy} \times 30), 59.4$ Gy $(1.8 \mathrm{~Gy} \times 33), 45 \mathrm{~Gy}$ $(1.8 \mathrm{~Gy} \times 25)$ with a simultaneous integrated boost (SIB) of $55 \mathrm{~Gy}(2.2 \mathrm{~Gy} \times 25)$ and $40 \mathrm{~Gy}(2 \mathrm{~Gy} \times 20)$ with a SIB of 50 Gy $(2.5 \mathrm{~Gy} \times 20)$. Contrast-enhanced $\mathrm{T} 1$ sequences, $\mathrm{T} 2$ and/or FLAIR sequences of MRI were co-registered with the planning $\mathrm{CT}$ imagines within the Oncentra External Beam ${ }^{\circledR}$ treatment planning system (version 4.5.2, Nucletron, 3905 TH Veenendaal, Netherlands).

Concomitant and adjuvant chemotherapy was administered according to the protocol of the EORTC 26,981/22981 NCIC CE.3 trial [7], with temozolomide and lomustine according to the protocol of the CeTeG/ NOA-09 trial [18] or with bevacizumab with $10 \mathrm{mg}$ per kilogram bodyweight every other week in analogy to Gutin et al. [19].

\section{Target volumes}

The gross tumour volume (GTV) included all contrastenhancing regions detected on T1-weighted MRI. For patients treated with $60 \mathrm{~Gy}$, the clinical target volume (CTV) was based on the GTV with a margin of up to $20 \mathrm{~mm}$ and the perifocal edema visible on the T2 or FLAIR sequence accounting for microscopic tumour spread. The planning target volume (PTV) was created by anatomical adaptation of the corresponding CTV and a subsequent addition of a 3 to $5 \mathrm{~mm}$ margin to compensate for possible deviations in patient positioning. For patients treated with $59.4 \mathrm{~Gy}$, the treatment volume receiving 50.4 Gy was created using the GTV with a $20 \mathrm{~mm}$ CTV margin and a $5 \mathrm{~mm}$ PTV margin and the boost volume receiving additional $9 \mathrm{~Gy}$ on a $10 \mathrm{~mm}$ GTV to PTV margin. For the patient treated with $45 \mathrm{~Gy}$ and a 55 Gy SIB, the 45 Gy volume was created on basis of the GTV with a $20 \mathrm{~mm}$ CTV margin expansion and a $3 \mathrm{~mm}$ PTV margin expansion and the SIB volume of $55 \mathrm{~Gy}$ on basis of a $10 \mathrm{~mm}$ GTV to PTV boost margin. In the patient treated with 40 Gy and a 50 Gy SIB, the 40 Gy volume was created on basis of the GTV with a $15 \mathrm{~mm}$ CTV margin expansion and a $3 \mathrm{~mm}$ PTV margin expansion and the SIB volume of $50 \mathrm{~Gy}$ on basis of a $5 \mathrm{~mm}$ GTV to PTV boost margin. For each case the overall GTV volume was calculated as the sum of all contrastenhancing foci.

\section{Dosimetrical parameters}

The dosimetrical parameters of the mean dose of the brain, the V30 and V45 and the D2 of the brain were assessed. Parameters V30 and V45 indicate the percentage of total brain tissue exposed to at least $30 \mathrm{~Gy}$ and 45 Gy, respectively. D2 describes the radiation exposure of the $2 \%$ brain tissue with the highest radiation exposure, measured in Gy.

\section{Statistical and survival analysis}

Statistical analysis was performed with $\mathrm{IBM}^{\odot} \mathrm{SPSS}^{\odot}$ Statistics (version 26, IBM ${ }^{\odot}$, Armonk, NY, USA). Descriptive statistical analysis was performed for patient characteristics, radiotherapy and dosimetric parameters. KaplanMeier estimator analyses were performed for overall and progression-free survival. Overall survival was calculated as the time interval between histological confirmation and the date of death or loss to follow-up. Progressionfree survival was assessed as the time interval between initiation of RT and the first imaging detection of progressive disease according to the RANO criteria [20] or loss to follow-up.

\section{Assessment of adverse events}

Adverse events, that occurred during or after the radiation treatment and which could have been linked to it, were evaluated and classified following the CTCAE 5.0 classification system.

\section{Results}

Patients

20 patients with multifocal high-grade glioma were examined, of which seven were female and 13 were 
male. The median age of all patients was 61 years (range 42-84 years). Median KPS prior to radiotherapy was 85 (range 50-100) and median KPS at the end of the radiotherapy was 80 (range 50-100). Patient characteristics for all patients are shown in Table 1.

\section{Histopathological diagnosis}

All patients underwent neurosurgical intervention prior to radiotherapy. 18 patients underwent stereotactic biopsy, while a resection was performed in two patients. Histological and molecular genetic examination of the collected tissue samples resulted in 18 IDH wild-type glioblastoma cases, one diffuse astrocytic glioma, IDH wild-type case with molecular features of glioblastoma and one anaplastic astrocytoma, IDH wild-type case. Examination of mutation of the IDH1 and IDH2 gene showed IDH1 and IDH2 wildtype in all cases. Examination of the MGMT promotor methylation status showed methylation of the MGMT promotor in 11 of 20 patients (55\%).

\section{Treatment}

Regarding radiotherapy prescription, 15 patients received 60 Gy $(2 \mathrm{~Gy} \times 30)$, three patients 59.4 Gy $(1.8 \mathrm{~Gy} \times 33)$, one patient 55 Gy $(2.2 \mathrm{~Gy} \times 25)$ and one patient 50 Gy $(2.5 \mathrm{~Gy} \times 20)$. Concomitant chemotherapy was administered in 18 patients. 16 patients were treated with temozolomide according to the protocol of the EORTC
26,981/22981 NCIC CE.3 trial, one patient with temozolomide and lomustine according to the CeTeG/NOA-09 trial and one patient with bevacizumab with $10 \mathrm{mg}$ per kilogram bodyweight every other week.

Adjuvant chemotherapy was administered with temozolomide according to the protocol of the EORTC 26,981/22981 NCIC CE.3 trial in nine patients, with temozolomide and lomustine according to the CeTeG/ NOA-09 trial in two patients and in one patient with bevacizumab with $10 \mathrm{mg}$ per kilogram bodyweight every other week.

Treatment at progression was best supportive care in 15 cases, combined bevacizumab and irinotecan treatment in two cases, reRT with concomitant temozolomide chemotherapy with 36 Gy $(2 \mathrm{~Gy} \times 18)$ in one case and temozolomide rechallange at first progression and with reRT with $39 \mathrm{~Gy}(3 \mathrm{~Gy} \times 13)$ within the GLIAA protocol at second progression in one case [21]. In one case, there was no progression at the time of data analysis.

\section{Target and dosimetrical volumes}

Average number of GTVs was three GTVs with a range from two GTVs up to nine GTVs. The median size of the sum of the GTVs was $26 \mathrm{~cm}^{3}$ (range $3.6-303.9 \mathrm{~cm}^{3}$ ). The examination of the dosimetrical parameters showed a median D2\% of 61.5 Gy. The percentage proportion of V30Gy and V45Gy was 59.9\% (range 33-79.7\%) and 40.7\% (range 14.9-64.1\%), respectively. The median

Table 1 Patient characteristics

\begin{tabular}{|c|c|c|c|c|c|c|c|c|c|}
\hline Pat & Age & Sex & Diag & WHO & IDH & MGMT & Resection & KPS pre RT & KPS post RT \\
\hline 1 & 50 & Male & $G B$ & IV & IDHWT & unmeth & biopsy & 70 & 70 \\
\hline 2 & 84 & Male & $\mathrm{GB}$ & IV & IDHWT & meth & biopsy & 80 & 80 \\
\hline 3 & 68 & Male & $G B$ & IV & IDHWT & meth & biopsy & 80 & 70 \\
\hline 4 & 70 & Male & $\mathrm{GB}$ & IV & IDHWT & meth & biopsy & 90 & 90 \\
\hline 5 & 74 & Female & GB & IV & IDHWT & meth & biopsy & 60 & 50 \\
\hline 6 & 62 & Male & $\mathrm{GB}$ & IV & IDHWT & unmeth & biopsy & 90 & 80 \\
\hline 7 & 63 & Male & GB & IV & IDHWT & meth & biopsy & 90 & 80 \\
\hline 8 & 50 & Female & $G B$ & IV & IDHWT & unmeth & biopsy & 90 & 80 \\
\hline 9 & 68 & Male & GB & IV & IDHWT & unmeth & biopsy & 60 & 50 \\
\hline 10 & 64 & Female & $G B$ & IV & IDHWT & unmeth & biopsy & 80 & 70 \\
\hline 11 & 53 & Male & GB & IV & IDHWT & unmeth & str & 90 & 80 \\
\hline 12 & 50 & Male & $\mathrm{GB}$ & IV & IDHWT & unmeth & biopsy & 90 & 80 \\
\hline 13 & 57 & Female & AA & III & IDHWT & meth & biopsy & 90 & 70 \\
\hline 14 & 42 & Female & GB & IV & IDHWT & meth & biopsy & 80 & 70 \\
\hline 15 & 62 & Male & $G B$ & IV & IDHWT & meth & gtr & 100 & 100 \\
\hline 16 & 50 & Female & $\mathrm{GB}$ & IV & IDHWT & meth & biopsy & 50 & 50 \\
\hline 17 & 57 & Male & $\mathrm{GB}$ & IV & IDHWT & meth & biopsy & 100 & 100 \\
\hline 18 & 54 & Female & $\mathrm{GB}$ & IV & IDHWT & meth & biopsy & 70 & 70 \\
\hline 19 & 60 & Male & $\mathrm{GB}$ & IV & IDHWT & unmeth & biopsy & 70 & 80 \\
\hline 20 & 69 & Male & $G B$ & IV & IDHWT & unmeth & biopsy & 100 & 90 \\
\hline
\end{tabular}


percentage of the high dose irradiated volume divided by the brain volume was 32.8 percent (range 12-63.2\%). Radiotherapy and dosimetric parameters for all patients are shown in Table 2.

\section{Survival}

Median survival after diagnosis was eight months (95\% KI 3.6-12.4 months) and median progressionfree survival after initiation of RT five months (95\% CI 2.8-7.2 months) (Fig. 2). Median survival and progression-free survival was not significantly different between patients with PTV volumes greater than $425.7 \mathrm{~cm}^{3}$ and patients with smaller PTV volumes (6 vs. 10 months, $p=0.24$; 5 vs. 5 months, $p=0.298$ ) or between patients with methylated and unmethylated MGMT promotors ( 7 vs. 9 months, $p=0.615$; 5 vs. 7 months, $p=0.804$ ). A trend towards longer median survival and progressionfree survival was seen for patients with KPS $>80$ prior to initiation of RT ( 9 vs. 6 months, $p=0.076$; 5 vs. 3 months, $p=0.1)$ as well as for patients with KPS $\geq 80$ at the end of RT (10 vs. 6 months, $p=0.025,7$ vs. 5 months, $p=0.154$ ).

\section{Adverse events}

Grade 2 toxicities were detected in eight cases including alopecia, cushingoid symptoms, fatigue, hyperglycaemia, intracranial haemorrhage, platelet count decrease, thromboembolic events, and vomiting. Grade 3 toxicities were detected in four cases with three cases of increasing cerebal edema and one case of febrile neutropenia and one case of seizure. One grade 4 toxicities with severe white blood cell count decrease related to concomitant chemotherapy was observed. Subclassification of these adverse events according to CTCAE v. 5.0 is shown in Table 3. For grade 2 toxicities, V30, V45 and the D2 values were above or equal to median in $4 / 8,3 / 8$ and $4 / 8$ cases, respectively. For grade 3 and 4 toxicities V30, V45 and the D2 values were above or equal to median in $0 / 4$, $0 / 4$ and $2 / 4$ cases, respectively.

\section{Discussion}

There are no definitive standards for the diagnosis and treatment of patients with multifocal high-grade gliomas. The current WHO classification of tumours of the central nervous system does not differentiate between multifocal and unifocal high-grade gliomas [2], although a number of studies on the histopathology of multifocal high-grade gliomas postulate, that distinct histopathological differences are observed [3-6]. Current guideline recommendations do not address multifocal high-grade glioma separately from the unifocal presentation of the disease [10]. Since few investigator initiated trials on RT treatment exist [22], it is no surprise that there is only very limited evidence for the radiotherapeutic treatment of patients with multifocal glioblastoma.

For a better understanding of the multifocal form of high-grade glioma, we examined a set of 20 unselected multifocal high-grade glioma cases, treated with conventionally fractionated, limited field RT with modern techniques including 3D conformal, IMRT and VMAT with or without concomitant chemotherapy. The focus of this case series was the assessment of the treatment outcomes in terms of progression-free and overall survival and treatment related adverse events for conventionally fractionated RT limited-field radiation treatment regimens. The VMAT technique, which enables more advanced dose modulation in glioblastoma treatment planning such as hippocampus [23, 24] and normal tissue sparing [25], was applied in almost half of the cohort, i.e. in nine of the 20 cases.

Despite an aggressive treatment approach, progression-free and overall survival in the present cohort were markedly shorter than in comparable high-grade glioma cohorts with predominantly unifocal tumours treated with RT and concomitant daily temozolomide, with a median overall survival of up to 15.7 months $[7,8,26]$. When comparing the present cohort to other cohorts treated with radiotherapy and daily administration of temozolomide without prior surgical resection, overall survival times are comparable with 7 vs. 9.2 months, respectively [15]. In previous RT case series of multifocal high-grade glioma patients treated with modern treatment techniques, the overall survival was comparable to our case series, with reported median overall survival times in the range between 8.2 months [6], 8.7 months [13] and 11.5 months [16].

Shortcomings of the study are its retrospective nature, the limited number of patients and also the heterogeneity of the treatment regimens used. Due to the rarity of the disease and the long period of time during which patients were included, different radiation doses and techniques were used. The predominant irradiation technique applied until 2014 was 3D conformal RT, followed by IMRT until 2016 and VMAT from 2017 onwards. Chemotherapy regimens also changed over time. For example, the combination of temozolomide and lomustine according to the CeTeG/NOA-09 trial protocol [18] was introduced following the encouraging results presented at the SNO annual meeting in 2017. In contrast, the NOA-05 trial including 35 patients with gliomatosis cerebri treated with primary chemotherapy with procarbazine and lomustine showed remarkable median progression-free and overall survival times of 14 months and 30 months, respectively. The phase 2 setting of this chemotherapy study is of course different to this unselected real life cohort, therefore the results are not fully 


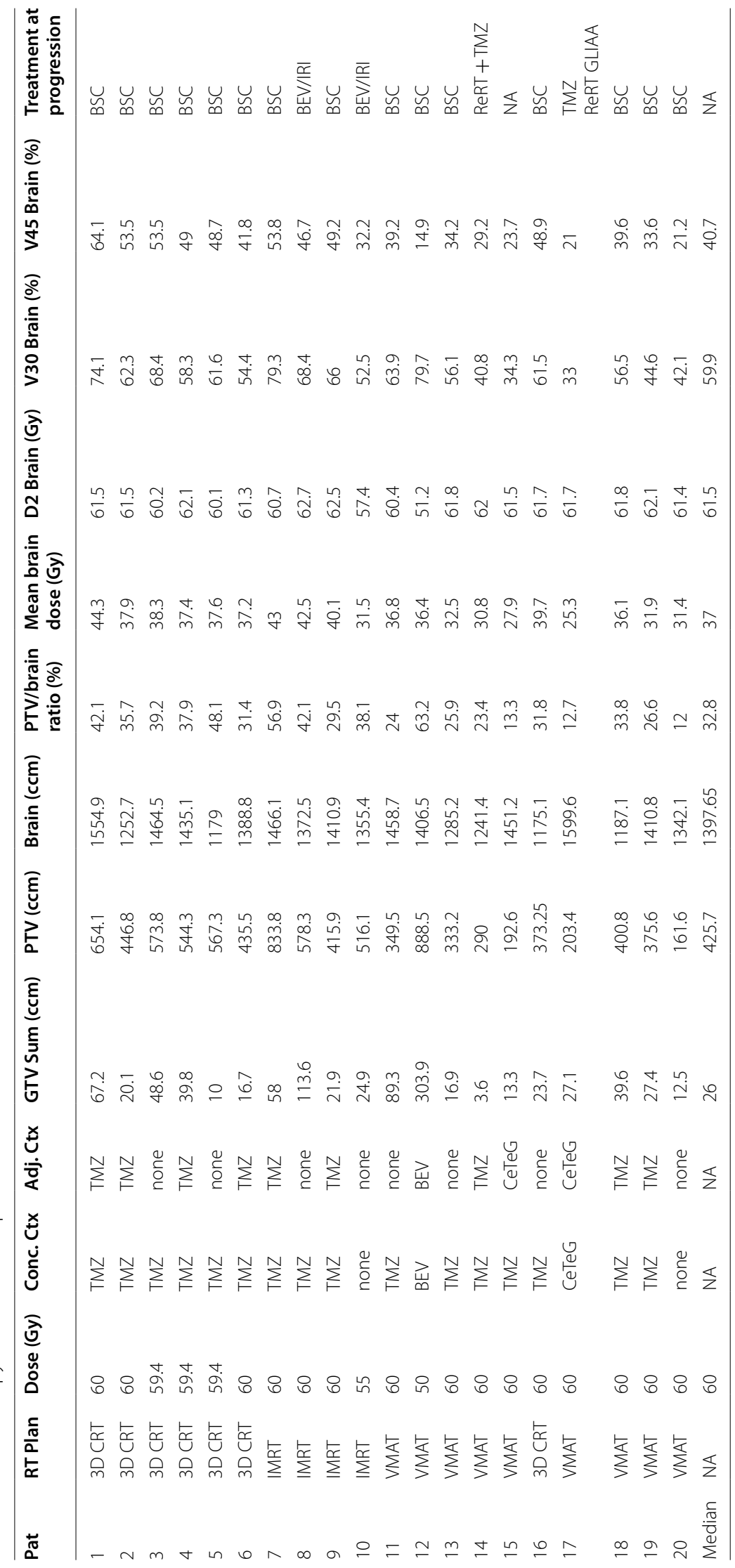


Table 3 Adverse events

\begin{tabular}{|c|c|c|c|c|}
\hline Pat & Grade 1 toxicities & Grade 2 toxicities & Grade 3 toxicities & Grade 4 toxicities \\
\hline 1 & $\begin{array}{l}\text { Fatigue } \\
\text { Headache }\end{array}$ & - & Seizure & - \\
\hline 2 & Fatigue & - & - & - \\
\hline 3 & $\begin{array}{l}\text { Alopecia } \\
\text { ALT and AST increase } \\
\text { Fatigue }\end{array}$ & - & - & - \\
\hline 4 & Dermatitis & - & - & - \\
\hline 5 & $\begin{array}{l}\text { Alopecia } \\
\text { Dermatitis } \\
\text { Fatigue }\end{array}$ & Thromboembolic event & - & - \\
\hline 6 & $\begin{array}{l}\text { Alopecia } \\
\text { Fatigue } \\
\text { Headache }\end{array}$ & - & - & - \\
\hline 7 & $\begin{array}{l}\text { Blurred vision } \\
\text { Cognitive disturbance } \\
\text { Dizziness }\end{array}$ & $\begin{array}{l}\text { Cushingoid } \\
\text { Platelet count decrease } \\
\text { Vomiting }\end{array}$ & - & - \\
\hline 8 & $\begin{array}{l}\text { Alopecia } \\
\text { Dysphasia } \\
\text { Headache }\end{array}$ & Intracranial hemorrhage & - & - \\
\hline 9 & Fatigue & - & - & - \\
\hline 10 & $\begin{array}{l}\text { Alopecia } \\
\text { Fatigue } \\
\text { Headache } \\
\text { Trigeminal nerve disorder }\end{array}$ & - & - & - \\
\hline 11 & $\begin{array}{l}\text { Alopecia } \\
\text { Blurred vision } \\
\text { Dysphasia } \\
\text { Fatigue } \\
\text { Headache } \\
\text { Vomiting }\end{array}$ & - & - & - \\
\hline 12 & $\begin{array}{l}\text { Fatigue } \\
\text { Hypersomnia } \\
\text { Memory impairment }\end{array}$ & $\begin{array}{l}\text { Cushingoid } \\
\text { Hyperglycemia }\end{array}$ & - & - \\
\hline 13 & $\begin{array}{l}\text { Dermatitis } \\
\text { Fatigue }\end{array}$ & Platelet count decrease & Cerebral edema & $\begin{array}{l}\text { Febrile neutropenia } \\
\text { White blood cell decrease }\end{array}$ \\
\hline 14 & Fatigue & $\begin{array}{l}\text { Alopecia } \\
\text { Thromboembolic event }\end{array}$ & & \\
\hline 15 & Fatigue & - & - & - \\
\hline 16 & $\begin{array}{l}\text { Alopecia } \\
\text { Fatigue } \\
\text { Headache }\end{array}$ & - & Cerebral edema & - \\
\hline 17 & ALT and AST increase & - & & - \\
\hline 18 & $\begin{array}{l}\text { Alopecia } \\
\text { Fatigue }\end{array}$ & Platelet count decrease & Cerebral edema & - \\
\hline 19 & $\begin{array}{l}\text { Alopecia } \\
\text { Fatigue }\end{array}$ & - & - & - \\
\hline 20 & - & $\begin{array}{l}\text { Alopecia } \\
\text { Fatigue }\end{array}$ & - & - \\
\hline
\end{tabular}

comparable. Furthermore, it has also to be taken into account that one third of the patients of the NOA-05 trial received radiotherapy after the primary chemotherapy [27].

One of the main reasons for the poor overall survival of multifocal high-grade glioma patients could be the reduced performance status of the patients, which was also evident in the present cohort with a median KPS of 85 prior to the initiation of RT and 80 at the end of RT, respectively. A KPS above median prior to and at the end of RT, respectively, showed a trend towards longer survival in this series, even though statistical evaluations have to be looked at with caution due to the small number of cases. 
Histopathologically, it has been discussed that the higher phenotypic aggressiveness of multifocal glioma itself might explain the poorest survival of all glioma subtypes $[6,28]$. The risk of refractory edema caused by large tumour infiltration and large RT treatment volumes with the prolonged need for dexamethasone after the completion of RT can also be discussed as a reason for poorer overall survival in patients with multifocal tumours. Interestingly, the three cases with grade 3 edema were cases with PTV volume below or in the range of the median, so the PTV volume by itself may not be the determining factor for the occurrence of edema after radiotherapy.

Whole brain radiotherapy (WBRT), which was the standard of care prior to the introduction of $3 \mathrm{D}$ conformal RT had considerable worse treatment outcomes with reported median overall survival times of only 3.7 months [13]. However, a recently reported monocentric case series of WBRT with concomitant and adjuvant TMZ chemotherapy in newly diagnosed multifocal glioblastoma patients reported a comparable overall survival of 10 months in median. Reported toxicities of this WBRT series were comparable to the limited field RT of this series with three grade 3 toxicities and one grade 4 toxicity [17].

A recent large-scale study initiating a nomogram for survival prediction of glioblastoma patients and a subsequent validation study have shown that a low KPS and lack of gross total resection, as present in the current case series, are significantly correlated with poorer overall survival $[29,30]$. Of note, multifocality itself was not included in this nomogram, possibly because of the rarity of this condition [29, 30]. In contrast, radiomics approaches, which are increasingly used for prognostic assessment of glioblastoma patients, multifocality is used as one of the main imaging features [31-33].

Large database studies have shown that concomitant systemic treatment with temozolomide has a benefit specifically in patients who could not undergo a surgical resection of the tumour, in both unifocal and multifocal growth patterns $[1,15]$. Nevertheless, further information about toxicities related to concomitant temozolomide in multifocal high-grade glioma patients could not be determined in these studies, as it was not documented in the databases. In our series, concomitant chemotherapy with temozolomide was applied in 17 patients with mostly acceptable toxicity, but one patient developed a grade 4 leukopenia.

In our unselected limited field RT cohort, adverse events were manageable despite the high percentages of irradiated brain volume of up to 63.2 percent. Only one case with a grade 4 toxicity was detected, which was not related to radiation but to concomitant chemotherapy, i.e. a severe decrease in white blood cells associated resulting in neutropenic fever. Grade 3 toxicities consisted of one case with new-onset seizure possibly related to radiation treatment and increasing cerebral edema in three cases, which did not appear to be related to the size of the PTV volume or above median values of V30, V45 and D2 of the brain.

\section{Conclusion}

In this case series, multifocal high-grade glioma could be treated safely with conventionally fractionated RT with concomitant and adjuvant TMZ chemotherapy. Prospective studies are warranted to select the best treatment regimen for multifocal high-grade glioma patients to improve the oncological outcome.

\section{Authors' contributions}

DF, RS and MN created the retrospective study design. MN, SC and CB prepared the original radiation treatment plans. DF, RS and $\mathrm{JH}$ evaluated the radiotherapy and dosimetric parameters. DF, RS, RB and $\mathrm{IH}$ evaluated the adverse events after radiotherapy. RF performed neuroradiological assessment of multifocality on MRI. MD provided neuropathological information. DF and RS prepared the manuscript. MN, SC and NT revised the manuscript. All authors read and approved the final manuscript.

\section{Funding}

Open Access funding enabled and organized by Projekt DEAL. Open Access funding provided by the German Cancer Consortium (DKTK).

\section{Availability of data and materials}

All data generated or analysed during this study are included in this published article.

\section{Declarations}

Ethics approval and consent to participate

The local ethics committee approved the study protocol of the retrospective analysis (study number 20-255).

Consent for publication

Not applicable.

Competing interests

The authors declare that they have no competing interests.

\section{Author details}

${ }^{1}$ Department of Radiation Oncology, University Hospital, LMU Munich, Munich, Germany. ${ }^{2}$ German Cancer Consortium (DKTK), partner site, Munich, Germany. ${ }^{3}$ German Cancer Research Center (DKFZ), Heidelberg, Germany. ${ }^{4}$ Institute of Neuroradiology, University Hospital, LMU Munich, Munich, Germany. ${ }^{5}$ Department of Neurosurgery, University Hospital, LMU Munich, Munich, Germany. ${ }^{6}$ Institute of Neuropathology, Faculty of Medicine, LMU Munich, Munich, Germany.

Received: 9 July 2021 Accepted: 13 Auqust 2021

Published online: 28 August 2021

\section{References}

1. Haque W, Thong Y, Verma V, Rostomily R, Brian Butler E, Teh BS. Patterns of management and outcomes of unifocal versus multifocal glioblastoma. J Clin Neurosci. 2020;74:155-9.

2. Louis DN, Perry A, Reifenberger G, von Deimling A, Figarella-Branger D, Cavenee WK, et al. The 2016 World Health Organization Classification of 
Tumors of the Central Nervous System: a summary. Acta Neuropathol. 2016;131:803-20.

3. Abou-El-Ardat K, Seifert M, Becker K, Eisenreich S, Lehmann M, Hackmann K, et al. Comprehensive molecular characterization of multifocal glioblastoma proves its monoclonal origin and reveals novel insights into clonal evolution and heterogeneity of glioblastomas. Neuro Oncol. 2017;19:546-57.

4. Karlowee V, Amatya VJ, Hirano H, Takayasu T, Nosaka R, Kolakshyapati $\mathrm{M}$, et al. Multicentric glioma develops via a mutant IDH1-independent pathway: immunohistochemical study of multicentric glioma. Pathobiol: J Immunopathol Mol Cell Biol. 2017;84:99-107.

5. Liu Q, Liu Y, Li W, Wang X, Sawaya R, Lang FF, et al. Genetic, epigenetic, and molecular landscapes of multifocal and multicentric glioblastoma. Acta Neuropathol. 2015;130:587-97.

6. Paulsson AK, Holmes JA, Peiffer AM, Miller LD, Liu W, Xu J, et al. Comparison of clinical outcomes and genomic characteristics of single focus and multifocal glioblastoma. J Neurooncol. 2014;119:429-35.

7. Stupp R, Mason WP, van den Bent MJ, Weller M, Fisher B, Taphoorn MJ, et al. Radiotherapy plus concomitant and adjuvant temozolomide for glioblastoma. N Engl J Med. 2005;352:987-96.

8. Stupp R, Hegi ME, Mason WP, van den Bent MJ, Taphoorn MJ, Janzer RC, et al. Effects of radiotherapy with concomitant and adjuvant temozolomide versus radiotherapy alone on survival in glioblastoma in a randomised phase III study: 5-year analysis of the EORTC-NCIC trial. Lancet Oncol. 2009;10:459-66.

9. Perry JR, Laperriere N, O'Callaghan CJ, Brandes AA, Menten J, Phillips C, et al. Short-course radiation plus temozolomide in elderly patients with glioblastoma. N Engl J Med. 2017;376:1027-37.

10. Weller M, van den Bent M, Tonn JC, Stupp R, Preusser M, Cohen-JonathanMoyal E, et al. European Association for Neuro-Oncology (EANO) guideline on the diagnosis and treatment of adult astrocytic and oligodendroglial gliomas. Lancet Oncol. 2017;18:e315-29.

11. Sulman EP, Ismaila N, Armstrong TS, Tsien C, Batchelor TT, Cloughesy T, et al. Radiation therapy for glioblastoma: American Society of Clinical Oncology Clinical Practice guideline Endorsement of the American Society for Radiation Oncology Guideline. J Clin Oncol : Off J Am Soc Clin Oncol. 2017:35:361-9.

12. Niyazi M, Brada M, Chalmers AJ, Combs SE, Erridge SC, Fiorentino A, et al. ESTRO-ACROP guideline "target delineation of glioblastomas." Radiother Oncol: J Eur Soc Ther Radiol Oncol. 2016:118:35-42.

13. Showalter TN, Andrel J, Andrews DW, Curran WJ Jr, Daskalakis C, WernerWasik M. Multifocal glioblastoma multiforme: prognostic factors and patterns of progression. Int J Radiat Oncol Biol Phys. 2007;69:820-4.

14. Thomas RP, Xu LW, Lober RM, Li G, Nagpal S. The incidence and significance of multiple lesions in glioblastoma. J Neurooncol. 2013;112:91-7.

15. Kole AJ, Park HS, Yeboa DN, Rutter CE, Corso CD, Aneja S, et al. Concurrent chemoradiotherapy versus radiotherapy alone for "biopsy-only" glioblastoma multiforme. Cancer. 2016;122:2364-70.

16. Syed M, Liermann J, Verma V, Bernhardt D, Bougatf N, Paul A, et al. Survival and recurrence patterns of multifocal glioblastoma after radiation therapy. Cancer Manag Res. 2018;10:4229-35.

17. Lahmi L, Idbaih A, Rivin Del Campo E, Hoang-Xuan K, Mokhtari K, Sanson $M$, et al. Whole brain radiotherapy with concurrent temozolomide in multifocal and/or multicentric newly diagnosed glioblastoma. J Clin Neurosci. 2019:68:39-44.

18. Herrlinger U, Tzaridis T, Mack F, Steinbach JP, Schlegel U, Sabel M, et al. Lomustine-temozolomide combination therapy versus standard temozolomide therapy in patients with newly diagnosed glioblastoma with methylated MGMT promoter (CeTeG/NOA-09): a randomised, open-label, phase 3 trial. Lancet. 2019;393:678-88.

19. Gutin PH, Iwamoto FM, Beal K, Mohile NA, Karimi S, Hou BL, et al. Safety and efficacy of bevacizumab with hypofractionated stereotactic irradiation for recurrent malignant gliomas. Int J Radiat Oncol Biol Phys. 2009;75:156-63.

20. Wen PY, Macdonald DR, Reardon DA, Cloughesy TF, Sorensen AG, Galanis $E$, et al. Updated response assessment criteria for high-grade gliomas: response assessment in neuro-oncology working group. J Clin Oncol: Off J Am Soc Clin Oncol. 2010;28:1963-72.

21. Oehlke O, Mix M, Graf E, Schimek-Jasch T, Nestle U, Götz I, et al. Aminoacid PET versus MRI guided re-irradiation in patients with recurrent glioblastoma multiforme (GLIAA) — protocol of a randomized phase II trial (NOA 10/ARO 2013-1). BMC Cancer. 2016;16:769.

22. Cihoric N, Tsikkinis A, Minniti G, Lagerwaard FJ, Herrlinger U, Mathier E, et al. Current status and perspectives of interventional clinical trials for glioblastoma-analysis of ClinicalTrials.gov. Radiat Oncol. 2017;12:1.

23. Wee CW, Kim KS, Kim CY, Han JH, Kim YJ, Kim IA. Feasibility of hippocampus-sparing VMAT for newly diagnosed glioblastoma treated by chemoradiation: pattern of failure analysis. Radiat Oncol. 2020;15:98.

24. Kim KS, Wee CW, Seok JY, Hong JW, Chung JB, Eom KY, et al. Hippocampus-sparing radiotherapy using volumetric modulated arc therapy (VMAT) to the primary brain tumor: the result of dosimetric study and neurocognitive function assessment. Radiat Oncol. 2018;13:29.

25. Briere TM, McAleer MF, Levy LB, Yang JN. Sparing of normal tissues with volumetric arc radiation therapy for glioblastoma: single institution clinical experience. Radiat Oncol. 2017;12:79.

26. Nachbichler SB, Schupp G, Ballhausen H, Niyazi M, Belka C. Temozolomide during radiotherapy of glioblastoma multiforme : Daily administration improves survival. Strahlenther Onkol. 2017;193:890-6.

27. Glas M, Bähr O, Felsberg J, Rasch K, Wiewrodt D, Schabet M, et al. NOA05 phase 2 trial of procarbazine and lomustine therapy in gliomatosis cerebri. Ann Neurol. 2011;70:445-53.

28. Hassaneen W, Levine NB, Suki D, Salaskar AL, de Moura LA, McCutcheon $\mathrm{IE}$, et al. Multiple craniotomies in the management of multifocal and multicentric glioblastoma. Clinical article. J Neurosurg. 2011;114:576-84.

29. Gittleman H, Lim D, Kattan MW, Chakravarti A, Gilbert MR, Lassman AB, et al. An independently validated nomogram for individualized estimation of survival among patients with newly diagnosed glioblastoma: NRG Oncology RTOG 0525 and 0825. Neuro Oncol. 2017;19:669-77.

30. Kim N, Chang JS, Wee CW, Kim IA, Chang JH, Lee HS, et al. Validation and optimization of a web-based nomogram for predicting survival of patients with newly diagnosed glioblastoma. Strahlenther Onkol. 2020;196:58-69.

31. Mazurowski MA, Desjardins A, Malof JM. Imaging descriptors improve the predictive power of survival models for glioblastoma patients. Neuro Oncol. 2013;15:1389-94.

32. Peeken JC, Hesse J, Haller B, Kessel KA, Nüsslin F, Combs SE. Semantic imaging features predict disease progression and survival in glioblastoma multiforme patients. Strahlenther Onkol. 2018;194:580-90.

33. Kocher M, Ruge Ml, Galldiks N, Lohmann P. Applications of radiomics and machine learning for radiotherapy of malignant brain tumors. Strahlenther Onkol. 2020;196:856-67.

\section{Publisher's Note}

Springer Nature remains neutral with regard to jurisdictional claims in published maps and institutional affiliations. 